\title{
THE IMPACT OF SALT ON THE QUALITY OF FRESH WHEAT NOODLE
}

\author{
- Research paper - \\ Yunfeng $\mathrm{HU}^{1}$, Jinjin WEI, Yuanyuan CHEN \\ College of Food Engineering and Biotechnology, Tianjin University of Science and \\ Technology, Tianjin 300457, China
}

\begin{abstract}
The purpose is to analyze the concentration-response relationship of salt on the rheological properties, cooking characteristic and microstructure of fresh noodle and investigate the influence rules of salt on rheological characteristics, cooking characteristics and microstructure of fresh noodle. The change rules of rheological parameters, cooking characteristics and microstructure were analyzed using the refined wheat flour as the experimental material, adding different proportion of salt ( 0 up to $5 \%$ weight on flour basis), making fresh noodles. Results showed that the dough formation time, stability time, the maximum tensile force and tensile range increased gradually, weakening degree and the best cooking time decreased gradually, in addition, the internal network structure was fine-meshed with the increase of salt content. But the tensile distance began to decline, the network structure became loose and the hole enlarged when adding amount surpassed 3\%. Taken together, adding $3 \%$ of the salt can improve the quality of fresh noodle. Research conclusions: the right amount of salt can improve the opaque quality index and tensile properties, reduce water absorption and optimum cooking time, enhance the internal network structure; but excessive salt will reduce the tensile properties of noodles and cooking characteristics, black or even destroy the production of internal network structure.
\end{abstract}

Key words: Fresh noodle, salt, rheological properties, cooking characteristic, microstructure

\section{INTRODUCTION}

Noodle is the traditional food of our country, which is third staple food after rice and steamed bread (Zhu, et al., 2007; Shi, et al., 2015). Along with the rising of living standards, people not only paying attention to the color, odour, taste and nutrition value, but also laying emphasis on the quality, such as toughness and texture of noodles. The current market, the emergence of fresh noodles are not resistant to cooking, taste sticky, biting strength and other issues, it is difficult to meet the high quality requirements (Preston, 1989). In the process of making noodles, a large number of non-oriented protein network structures embedded in starch granules were formed, and the formation of the network structure had a direct impact on the quality of noodles (Shi, et al., 2015).

Research shows that the salt will be dissociated from sodium and chloride ions after dissolved in water, which can make the flour absorb water quickly, so that improving noodle tensile resistance and ductility, making the gluten crunch, improving gluten network structure, enhancing the cohesive strength and reducing the breaking rate (Danno, et al., 1982; Wang, 2008). Some commercially available Hanging noodles and Hand-Pulled noodle improved its tensile properties by adding salt (Shi, et al., 2015). Similar studies have been conducted abroad, and Preston (1989) suggests that neutral salts affect the physical properties of dough by ionic strength and protein hydrophobicity. Danno (1982) and Moreira (2011) think that salt can reduce wheat flour dough water absorption, improve the stability time, forming time, and increase the tensile force, elongation and

\footnotetext{
${ }^{1}$ Corresponding author. Mailing address: hu-yf@163.com
} 
maximum tensile resistance. The effect of salt on noodle quality has been studied, but the specific data analysis of the relationship is still relatively short. In this paper, the effects of salt on the rheological properties, cooking characteristics

\section{MATERIALS AND METHODS}

Materials: Wheat flour was obtained from Lijin Foodstuff and Edible Oil corporation ltd(Tianjin, China), protein content in which is $12.2 \%$. The salt was from Zhongyan(Anhui, China).

Noodle preparation: Control noodle dough consisted of 100 parts of wheat flour and 32 parts of deionized water. Different levels of salts were added. On flour weight basis, salt was added at $0,1.0,2.0,3.0,5.0 \%$, which were dissolved in water prior to addition. Ingredients were mixed into crumbly dough using a doughmaker (SM-168SMurenking, Shepherd appliances, Shenzhen, China). The flocculent dough was got by mixing for 5 minutes and after that was placed in plastic wrap to rest for 20 minutes at $25^{\circ} \mathrm{C}$. The flocculent dough was then hand kneaded into a stiff mass and passed through a noodle roller (Atlas150, Marcato, Italy) to form a noodle sheet at a $0.8 \mathrm{~mm}$ roll gap setting, and then cut into patches beam width of $2 \mathrm{~mm}$ and length of $22 \mathrm{~cm}$.

Farinograph property of flour: To investigate the farinograph property of flour with a texture instrument (Dough LAB 2500, Perten Instruments $\mathrm{AB}$, Sweden). Prepare salt water (based on flour, $0 \%, 1 \%, 2 \%, 3 \%, 5 \%$ of the salt dissolved in water) and reserve. The farinograph property of flour was evaluated according to the method by standards association of China (2006). $50 \mathrm{~g}$ flour will be added to the flour dough kneading pot bowl, and then $16 \mathrm{~mL}$ salt water, its temperature is $\left(30 \pm 0.5^{\circ} \mathrm{C}\right)$, will be added to it when the temperature reaches $\left(30 \pm 0.2{ }^{\circ} \mathrm{C}\right)$. Knead into dough (Torque power: $(1.96 \pm 0.04) \mathrm{mN} \cdot \mathrm{m} / \mathrm{FU} \quad[(20 \pm 0.4) \mathrm{gf} \cdot \mathrm{cm} / \mathrm{FU}]$, Rotational speed:63r/min), and draw out the powder curve according to the power consumption during dough kneading. The flour quality index, water absorption rate, formation time, stability time and degree of weakening were measured. and internal network structure of the noodles were studied by changing the amount of salt added, and then provided the basis for the scientific application of salt in noodle production.

Tensile properties of fresh noodles: To investigate the tensile properties of fresh noodles with a texture instrument (TA.XT.Plus, Stable Micro System, England) according to the method by Shi (Shi, et al., 2002). Table 1 shows the parameters. The prepared fresh raw noodles are placed on the probe to measure the maximum tensile force and the stretching distance, and repeat three times.

Table 1. The parameters of dough tensile test

\begin{tabular}{|l|l|}
\hline Name & Parameter \\
\hline Sample & A/KIE \\
\hline speed before testing $(\mathrm{mm} / \mathrm{s})$ & 2.0 \\
\hline testing speed $(\mathrm{mm} / \mathrm{s})$ & 3 \\
\hline speed after testing $(\mathrm{mm} / \mathrm{s})$ & 10 \\
\hline test distance $/ \mathrm{mm}$ & 45 \\
\hline force/g & 5 \\
\hline
\end{tabular}

Cooking characteristics of fresh noodles: The cooking characteristics of fresh noodles were evaluated according to the method by Zhang (2005). $500 \mathrm{~g}$ noodle strands were placed in boiling water $(500 \mathrm{~m} \mathrm{~L})$ and cooked until the white core disappeared of the cross section, which is the best cooking time. Each sample was repeated three times. The noodle, which was cooked, will be removed, drain on paper for 5 min, and calculated the bibulous rate according to the formula 1:

$\mathrm{X}_{1}=\left(M_{2}-M_{1}\right) \div M_{1} \times 100 \%$

where (1), $X_{1}$ is the bibulous rate (\%), $M_{1}$ is the noodle weight before cooking $(\mathrm{g}), \mathrm{M}_{2}$ is the noodle weight after cooking $(\mathrm{g})$.

The cooking water was collected and its volume adjusted to $500 \mathrm{~mL}$ with deionized water. An aliquot $(100 \mathrm{~m} \mathrm{~L})$ of the diluted cooking water was then transferred to a washed, dried beaker and dried on an electric furnace to constant weight. The cooking loss was expressed as the formula 2 : 
$\mathrm{X}_{2}=\mathrm{M} \div \mathrm{G} \times 100 \%$

where (2), $X_{2}$ is the cooking loss rate (\%), $\mathrm{M}$ is dry matter weight ( $\mathrm{g}$, in $500 \mathrm{~mL}$ soup), $\mathrm{G}$ is noodle weight before cooking $(\mathrm{g})$.

Microstructure of noodle: The microstructure of noodle was observed using scanning electron microscope (SU1510, Japan) (Hui, et al., 2010; Semin, et al., 2010; Keeratipibul, et al., 2010). Each group of fresh noodle samples were placed

\section{RESULTS AND DISCUSSION}

Different salt content has obvious influence on the farinograph property of flour (Figure 1). Table 2 also showed that with the increase of salt content, the water absorption of dough gradually decreased and then increased gradually, while the dough formation time, stability time were increased gradually, and the weakening degree decreased gradually. In general, the greater the dough water absorption, the formation time, the stability time, the smaller the degree of weakening, the better the flour dough properties (Liu, 2008). It can be seen that adding the right amount of salt into the flour can improve the flour quality. It can obviously improve the in the freezer (Ameritech, Tianjin, China) at $-80^{\circ} \mathrm{C}$ for $12 \mathrm{~h}$ pre freezing and then put into a vacuum freeze dryer(FD8-3, GOLD-SIM, America) dried for $24 \mathrm{~h}$. Tapping the freeze-dried samples to make the natural fracture, the appropriate size of the sample block was selected to scan and take a picture. Scanning magnification selected $\times 1000, \times 500$ and $\times 200$.

stability and resistance of the dough, and increase the gluten strength. The main reason may be that the salt and dough compete for moisture, occupy the position of binding water in the dough, and change the hydrophobic effect of the protein. In addition, under the action of salt ions, amino acid gluten surface electrostatic shielding, weaken the electrostatic repulsion of gluten, internal protein polymerization, which results in reducing water absorption, and increasing the dough stability time (Xing, et al., 2016; Linlaud, et al., 2009; Galal , et al., 1978; Butow, et al., 2007).

Table 2. Effects of different salt contents on farinograph parameter of flour

\begin{tabular}{|l|l|l|l|l|}
\hline Proportion, \% & $\begin{array}{l}\text { Water } \\
\text { absorption, \% }\end{array}$ & $\begin{array}{l}\text { Development } \\
\text { time, min }\end{array}$ & $\begin{array}{l}\text { Stability time, } \\
\text { min }\end{array}$ & $\begin{array}{l}\text { Tolerance index, } \\
\text { FU }\end{array}$ \\
\hline $0 \%$ & 62.1 & 3.2 & 4.9 & 132.6 \\
\hline $1 \%$ & 60.4 & 4.4 & 7.6 & 94.9 \\
\hline $2 \%$ & 60.1 & 5.2 & 8.7 & 93.3 \\
\hline $3 \%$ & 50.5 & 5.4 & 10.3 & 68.8 \\
\hline $5 \%$ & 52.6 & 6.1 & 18.1 & 31.1 \\
\hline
\end{tabular}

Figure 2 shows the effect of salt content on the tensile properties of fresh noodles. With the increase of salt concentration, the maximum tensile strength and tensile distance at the beginning are unlikely to change, but the amount of salt in $1 \% \sim 2 \%$, tensile properties and stability of dough were obviously improved. When the adding amount is $3 \%$, the change is obvious, and then the tensile force continues to increases, but the tensile distance begins to decreases. This is consistent with the results of Butow (2007) and Lynch (2009). This is because that the proper amount of salt helps produce the dough network structure, improve the gluten network structure, make the tensile force increases, make the tensile properties and dough stability better and improve the quality of dough. However, when salt is added too much, some salt ions compete with flour to prevent or even destroy the formation of gluten network, which leads to the decrease of ductility.

The salt content also has a great impact on the best cooking time, water absorption rate and loss rate of noodle. Figure 3 indicates that the best cooking time is shorter and shorter with the increase of salt content, and the time was shorten about 1 minutes when the amount of added up to $5 \%$. 


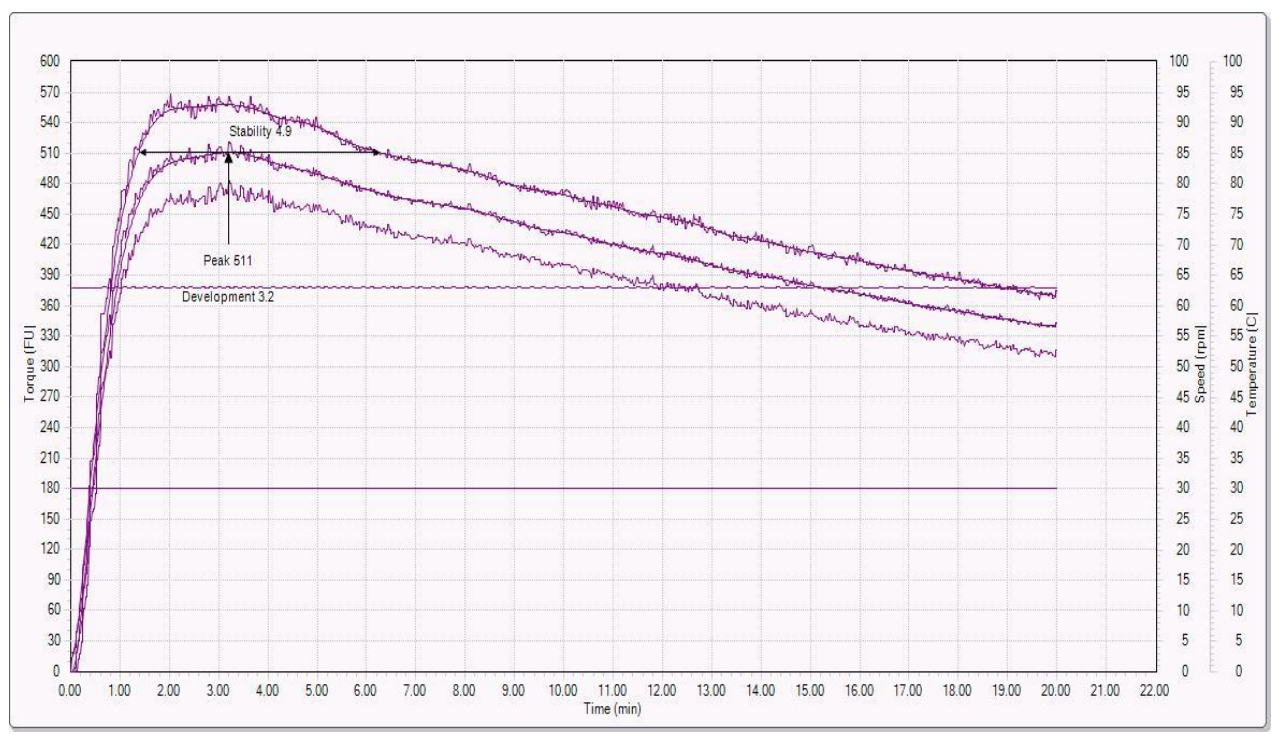

A
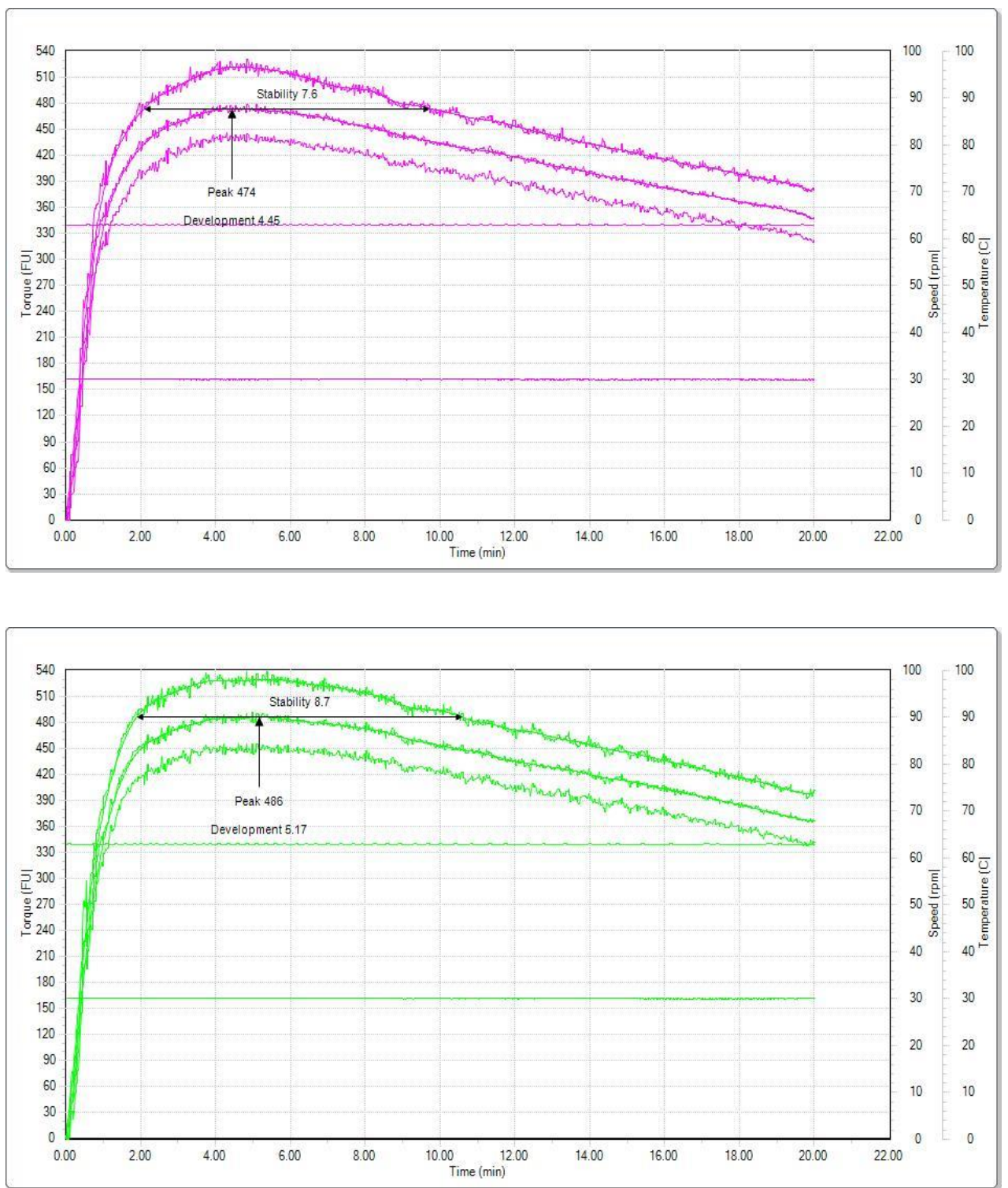

C 


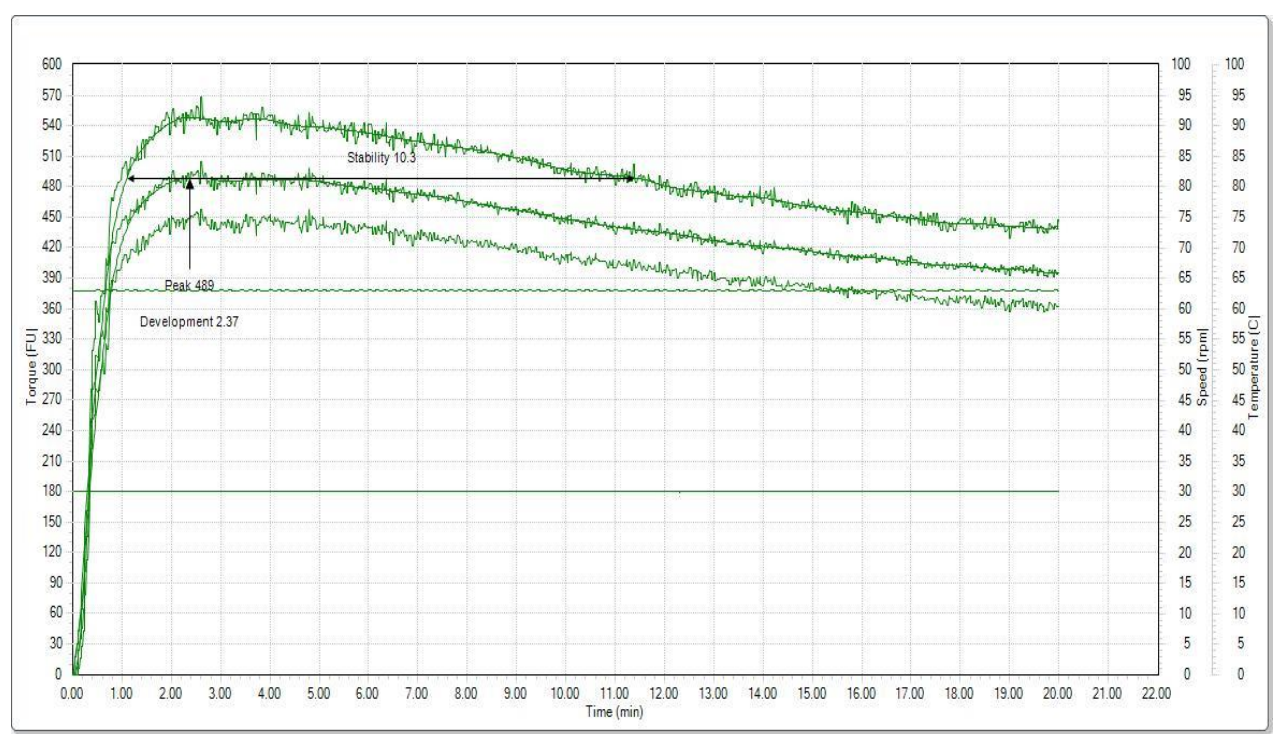

$\mathrm{D}$

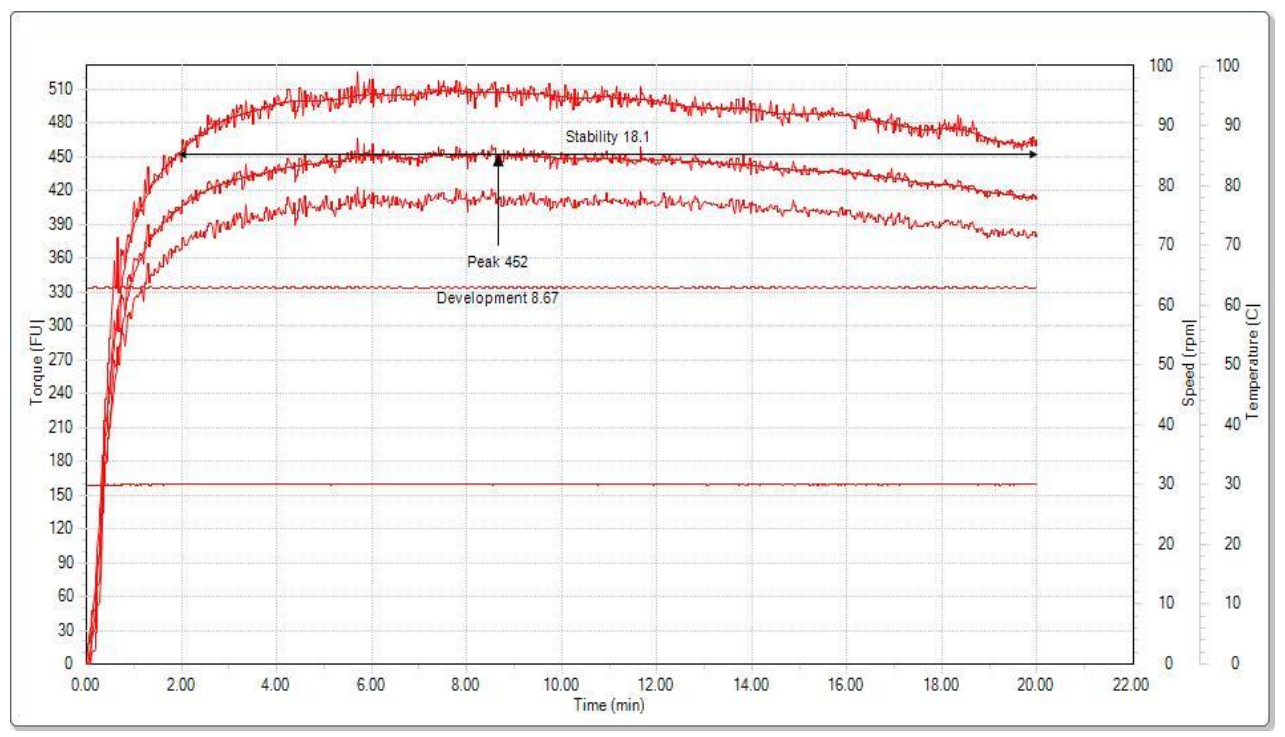

$\mathrm{E}$

Figure 1. Effects of salt on farinograph parameter of dough. A: $0 \% ; \mathrm{B}: 1 \%$; C: $2 \%$; D: $3 \%$; E: $5 \%$;

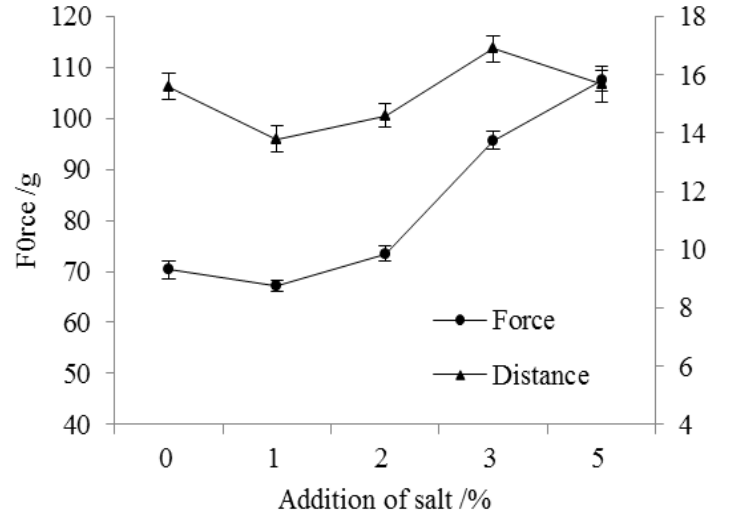

Figure 2. Effects of the salt addition to wet raw noodles on the changes of tensile properties

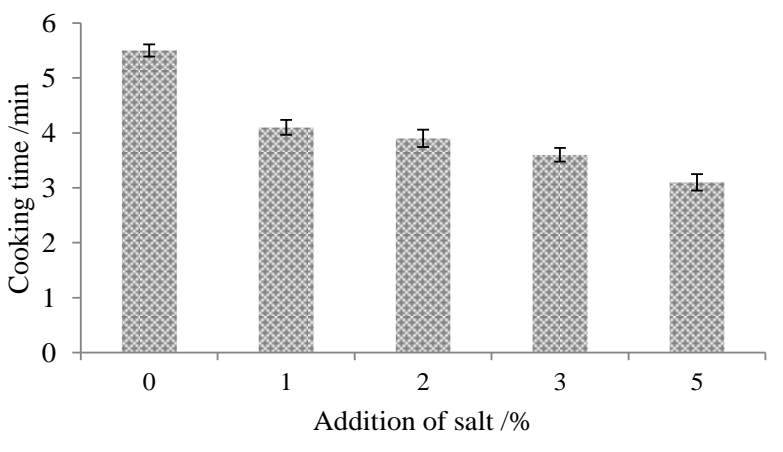

Figure 3. Effects of the salt addition to wet raw noodles on the changes of the best cooking time 
Figure 4 shows that the water absorption rate decreased with the increase of the amount of adding water, and the water absorption rate decreased from $67.5 \%$ to $60.2 \%$, when the salt content increased from $0 \%$ to $2 \%$. Then the water absorption stopped falling and remained unchanged, the lowest water absorption was $59.8 \%$, when the salt content is $3 \%$, with the increase of the amount of salt. Finally, the noodles bibulous rate began to rise slowly with the continuously increase of the amount of salt. Figure 4 also shows that the loss rate of noodle compared with the control group decreased slightly after adding $1 \%$ salt. Then loss rate has a slow upward trend with the increase of the amount of salt. The reasons may be that the salt increased the osmotic pressure of dough, which accelerates the speed of the water molecules entering the noodles, accelerates the maturity of the noodles, and shortens the cooking time. In addition, the proper amount of salt can improve the gluten network structure, which makes the surface of noodle smoother, reduce the water absorption and loss rate. At this point, it can be observed that the turbidity of soup of cooking noodle is low. However, when the salt content is more than $3 \%$, the lower degree of hydration of gluten protein led to the internal structure of noodles is not close, which speeds up the contact with water. Therefore the noodles are more likely to be cooked (Wang, 2008), even appeared the salt precipitation phenomenon, noodles poor shape, rough surface, water absorption rate and loss rate increased significantly, soup become turbid.

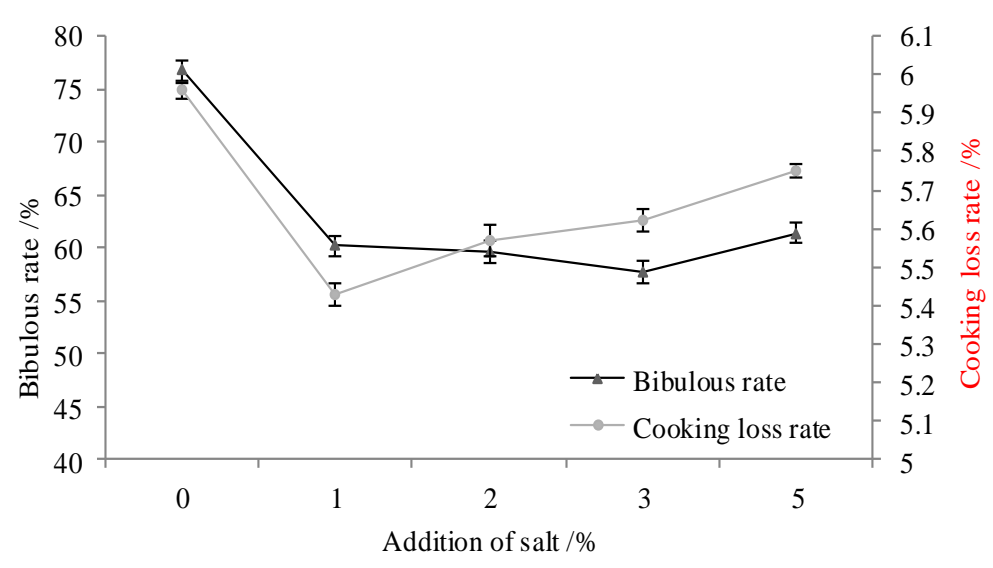

Figure 4. Effects of the salt addition to wet raw noodles on the changes of bibulous rate and loss rate

As can be seen from Figure 5, with the increase of salt content, the network structure is more and more dense, and when the amount of salt is $3 \%$, the network structure began to appear holes, and when the amount of salt is $5 \%$, the hole is more. According to Lynch (2009), it can theoretically be assumed that salt water has a strong penetration, resulting in flour absorption of water quickly in knead dough, which promotes and improves the formation of gluten formation network. From the Figures $5 \mathrm{~b}$ and c can clearly see the spherical starch granules and bright flaky gluten network protein. Figure $5 \mathrm{~b}$ shows that a lot of starch particles are exposed. With the increase of salt content, starch particles are gradually wrapped by gluten and forming a dense network structure. When the amount of salt is 3\%, the starch particles began to expose. When the amount of salt is $5 \%$, the gluten is destroyed. Large area of sequins into small sequins, and more starch particles are exposed. 

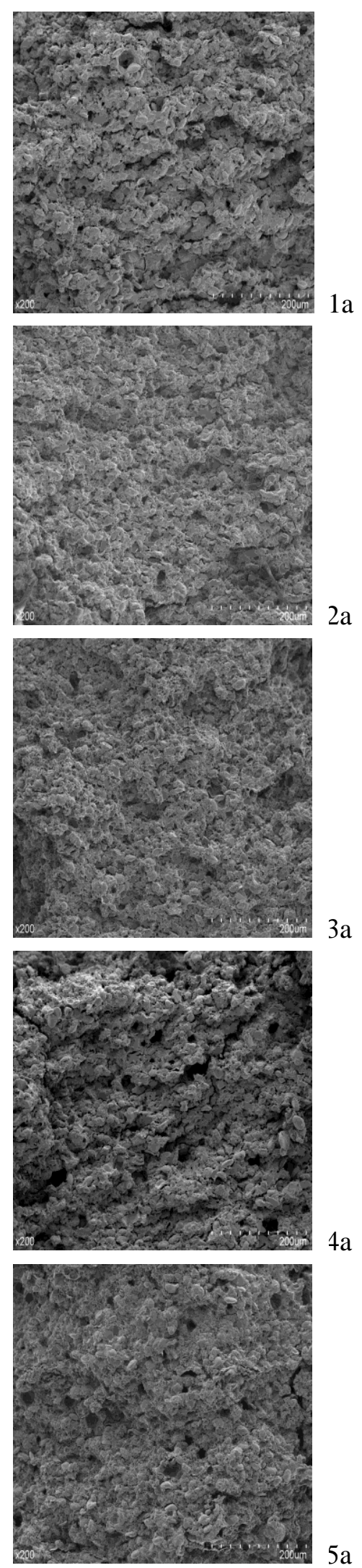
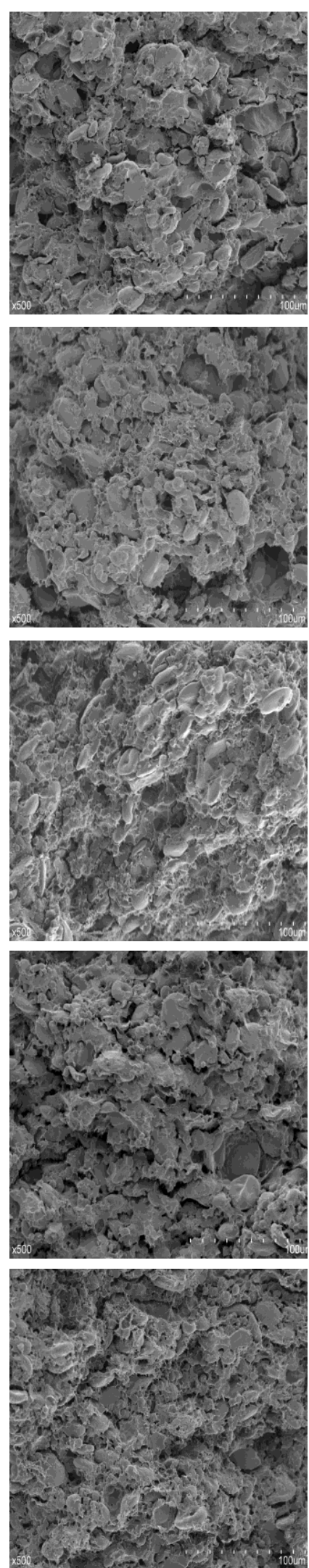

$1 \mathrm{~b}$

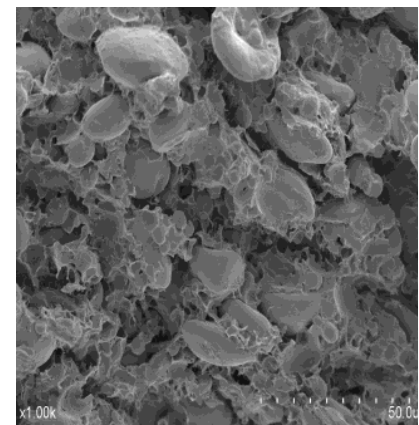

$1 \mathrm{c}$

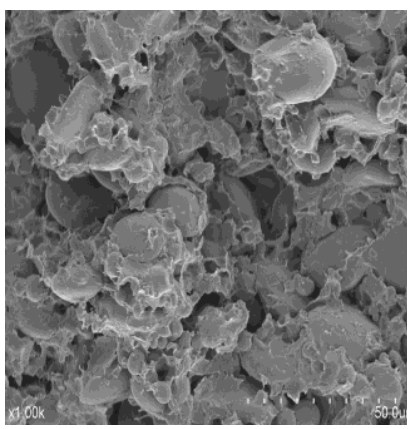

$2 c$

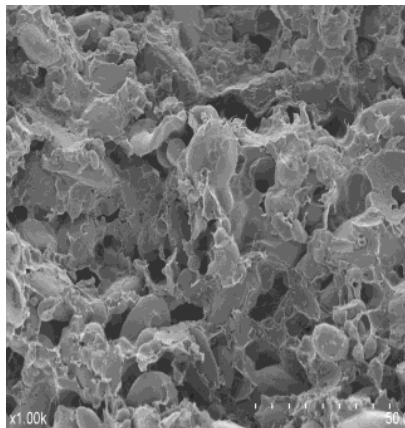

$3 b$

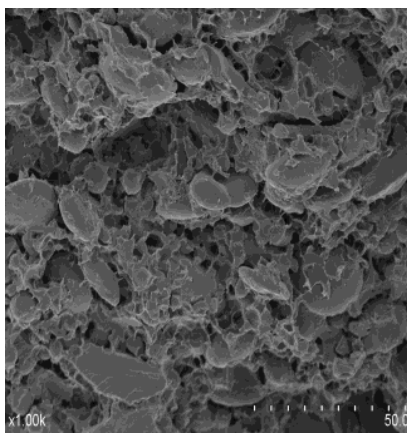

$3 c$

$4 \mathrm{c}$

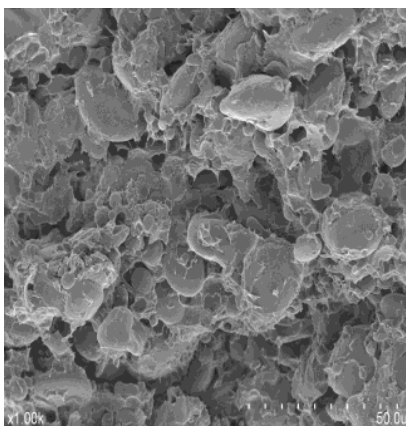

$5 c$

Figure 5. SEM of noodle $(1,2,3,4,5$ respectively are the photos of the amount of salt is $0 \%, 1 \%, 2 \%$, $3 \%, 5 \%, \mathrm{a}, \mathrm{b}, \mathrm{c}$ are the magnification for $\times 200, \times 500, \times 1000$ ) 


\section{CONCLUSIONS}

The formation time and stability time of dough increased, weakening degree decreased, the maximum tensile force and stretching distance of noodle increased, the optimum cooking time is shortened, the internal network structure improved compact with the increase of the amount of salt. The stretching distance of noodles began to decline, the internal network structure was loose, and the holes became larger when the amount of added salt was more than $3 \%$. On the whole, adding $3 \%$ salt can improve the quality of fresh noodles. In short: the amount of salt can improve the farinograph quality index, tensile properties of noodle, reduce the water absorption rate and the best cooking time, improve the internal network structure; but excess salt will reduce tensile properties, cooking properties, hinder or even destroy the internal network structure.

\section{ACKNOWLEDGEMENTS}

This work was financially supported by Tianjin science and technology plan projects (16YFZCNC00680), it was supported by Key Laboratory of Food Nutrition and Safety, Ministry of Education, Tianjin University of Science and Technology.

\section{REFERENCES}

1. Butow, B. J., Gras, P. W., Haraszi, R., \& Bekes, F. (2007). Effects of different salts on mixing and extension parameters on a diverse group of wheat cultivars using 2-g mixograph and extensigraph methods. Cereal Chemistry, 79(6), 826-833.

2. Danno G, Hoseney RC. (1982). Effect of sodium chloride and sodium dodecyl sulfate on mixograph properties. Cereal Chemistry, 59(3):202-204.

3. Galal, A. M., Varriano-Marston, E., \& Johnson, J. A. (1978). Rheological dough properties as affected by organic acids and salt. Cereal Chemistry,55(5), 683-691.

4. Hui, S., Yan, S., Jiang, W., Li, G., \& Macritchie, F. (2010). Contribution of lipid to physicochemical properties and mantou-making quality of wheat flour. Food Chemistry, 121(2), 332-337.

5. Keeratipibul, S., Luangsakul, N., Otsuka, S., Sakai, S., Hatano, Y., \& Tanasupawat, S. (2010). Application of the chinese steamed bun starter dough (csb-sd) in breadmaking. Journal of Food Science, 75(9), E596-E604.

6. Linlaud, N. E., Puppo, M. C., \& Ferrero, C. (2009). Effect of hydrocolloids on water absorption of wheat flour and farinograph and textural characteristics of dough. Cereal Chemistry, 86(4), 906190530-906190382.

7. Liu, Z. (2008). Application of farinograph and extensograph in the flour production. Agricultural Science \& Technology \& Equipment, (5):47-49.

8. Lynch, E. J., Bello, F. D., Sheehan, E. M., Cashman, K. D., \& Arendt, E. K. (2009). Fundamental studies on the reduction of salt on dough and bread characteristics. Food Research International, 42(7), 885-891.

9. Moreira R, Chenlo F, Torres MD. (2011). Effect of sodium chloride, sucrose and chestnut starch on rheological properties of chestnut flour doughs. Food Hydrocolloids, 25:1041-1050.

10. Preston KR. (1989). Effects of neutral salts of the lyotropic series on the physical dough properties of a Canadian red spring wheat flour. Cereal Chemistry, 66(3): 144-148.

11. Semin, O. O., Gulum, S., \& Serpil, S. (2010). The effects of gums on macro and micro-structure of breads baked in different ovens. Food Hydrocolloids, 23(8), 2182-2189.

12. Shi, J. L., Xin zhong, H. U., \& Ouyang, S. H. (2002). Development of research on noodle quality evaluation. Journal of Northwest Sci-Tech University of Agriculture and Forestry. 3(4):64-66.

13. Shi, L. F., Chen, J., Wang, Y. H., \& Bian, K. (2015). Influence of sodium metabisulphite on the extensibility of ramen dough. Journal of Henan University of Technology, 2:35-38.

14. Standars Association of China. (2006). Wheat flour-Physical characteristics of 
doughs-Determination of water absorption and rheological properties using a farinograp. GB/T 14614-2006. China Standards Press.

15. Wang, G. (2008). Effects of sodium chloride on noodle quality. Journal of the Chinese Cereals \& Oils Association., 23(6):184-187.

16. Y Xing, Y Zhang, R Liu, B Zhang, Y Wei, et al. (2016). The Effect of Inorganic Salts on Rheological Properties of Wheat Flour Doughs. Journal of Chinese Institute of Food Science and Technology, 16(9):77-86.

17. Zhang, S. B., Qi-Yu, L. U., \& Yan-Hong, L. V. (2005). The effect of lipid on noodle quality. Science \& Technology of Cereals Oils \& Foods. 6:66-69.

18. Zhu, Z. Q., \& Chen, X. (2007). Effects of salt on the rheological peculiarities and properties of steamed bun. Food Research \& Development, 28(9):40-43. 